\title{
Connecting Patients to Prescription Assistance Programs: Effects on Emergency Department and Hospital Utilization
}

\author{
Mason H. Burley, MPA; Kenn B. Daratha, PhD; Katherine Tuttle, MD; \\ John R. White, Jr., PA-C, PharmD; Michael Wilson, MPA; Kelly Armstrong, MSW; \\ Sterling McPherson, PhD; and Samuel Selinger, MD
}

\begin{abstract}
BACKGROUND: Manufacturer prescription assistance programs (PAPs) have been developed to provide medications at little or no cost to eligible patients. There are over 200 PAPs available from pharmaceutical companies, and each may have different eligibility requirements and assistance guidelines. A formalized community-based patient prescription coordinator can help patients navigate these programs by reviewing an applicant's financial information and medication requirements to identify which PAPs are most appropriate. Little is known, however, about whether providing such guidance is associated with a reduction in acute care utilization.
\end{abstract}

OBJECTIVE: To evaluate changes in emergency department and hospital utilization among patients who received care coordination and financial assistance with prescribed medications.

METHODS: This single-cohort interrupted time-series study included participants in eastern Washington state who enrolled in the Spokane Prescription Assistance Network (SPAN) program between March 1, 2009, and August 31, 2012. Referrals to the SPAN patient prescription coordinator were made by a social service agency or medical provider for patients who may have difficulty paying for prescribed medications. Initial patient contact occurred while the patient was still being treated in a clinic or hospital or through a direct visit to the coordinator's community-based office. Participants were contacted 6 months after the initial appointment and then annually thereafter to review current medications and health status. A review of electronic health records provided information on hospitalizations and emergency department visits in the 12 months before and after program entry.

RESULTS: Among SPAN participants $(n=310)$, emergency department and hospital encounters declined from 0.38 per participant in the year before enrollment to 0.20 encounters in the year following program entry. $A$ repeated-measures mixed-effects model indicated SPAN participation was associated with a $51 \%$ decline in the rate of emergency department and hospital utilization (incidence rate ratio $[\mathrm{IRR}]=0.49 ; 95 \% \mathrm{Cl}=0.31-0.77$; $P=0.002$ ). Observed effects differed by prescription class. Factor interactions revealed significant reductions in utilization for participants with prescribed pulmonary medications (IRR $=0.58 ; 95 \% \mathrm{Cl}=0.37-0.92 ; P=0.019$ ). Assistance with mental health (psychotropic) medications was associated with increased incidence of utilization (IRR $=2.07 ; 95 \% \mathrm{Cl}=1.32-3.24$; $P=0.001$ ). At the time of SPAN enrollment, $60 \%$ of participants had prescriptions for psychotropic medications.

CONCLUSIONS: A formalized patient prescription coordinator can help patients access prescribed medications at low cost and remain compliant with treatment plans. In a study of a coordination pilot program, reductions in hospital admissions and emergency department visits were observed following program participation.

J Manag Care Spec Pharm. 2016;22(4):381-87

Copyright $\odot 2016$, Academy of Managed Care Pharmacy. All rights reserved.

\section{What is already known about this subject}

In 2014, 13\% of American adults reported going without needed medication because of difficulty paying for prescriptions

Pharmaceutical manufacturers have initiated over 200 different prescription assistance programs (PAPs) to provide medications at little or no cost to income-eligible patients.

Use of PAPs is hindered by inconsistent eligibility requirements and reported difficulties in identifying and applying for appropriate programs. Limited research has been reported on enrollment counseling programs that are designed to increase access to PAPs.

\section{What this study adds}

This study examined a unique pilot program that employed a patient prescription coordinator to help patients access PAPs that offered prescriptions at reduced or no cost. This communitybased program was foundation funded, and consultations were provided to patients at no charge.

In the 12 months following program enrollment, patients who received coordinated prescription assistance experienced a 51\% reduction in the likelihood of visiting the emergency department or hospital, compared with the previous period.

This study highlights the potential benefits of direct assistance in helping patients access needed prescriptions though PAPs.

$\mathrm{P}$ rescription costs present a considerable financial burden for many individuals who require medications. In 2014, 1 in 8 American adults reported skipping medications because of difficulty paying for prescriptions. ${ }^{1}$ Currently, outof-pocket drug costs represent over half of all family health care spending for about 1 in 4 nonelderly adults in the United States. $^{2}$ In 5\% of American families, out-of-pocket prescription drug expenses make up 5\% or more of total family income. ${ }^{2}$ Over the next 10 years, per-capita out-of-pocket spending on prescription medication is projected to rise by 34\%. ${ }^{3}$ Overall pharmaceutical expenditures in the United States are also expected to rise in the coming years, as a result of greater use from an expanding population with chronic health conditions, availability of new specialty medications, and growth in the number of individuals gaining insurance following implementation of the Patient Protection and Affordable Care Act (PPACA) in 2014., 


\section{FIGURE 1 Sample Selection Flowchart}

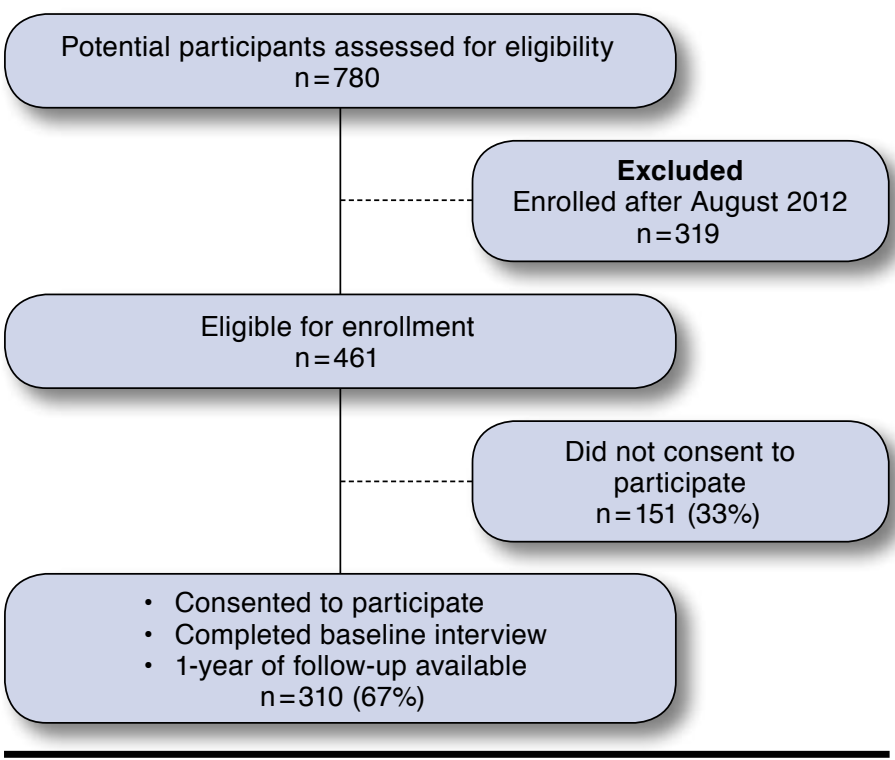

In order to improve access to prescription medications, pharmaceutical companies have established over 200 different prescription assistance programs (PAPs). ${ }^{6}$ These programs typically provide brand-name drugs at little or no cost to income-eligible patients. ${ }^{7}$ The actual retail cost of prescriptions obtained through PAPs may exceed the cost of available generic alternatives. However, for patients that qualify, free or reducedcost medications from PAPs may improve medication adherence by decreasing overall costs to the patient. A systematic review of interventions aimed at improving adherence reported that prescription drug cost reduction was as effective as more complex and costly approaches, such as case management and collaborative care. $^{8}$

PAPs are available from many pharmaceutical companies, but these programs remain underutilized by targeted populations. ${ }^{9-11}$ Health care providers and pharmacists do not typically dedicate resources to helping patients access the many programs available from pharmaceutical companies. ${ }^{12,13}$ In a survey of 215 safety-net facilities in California, Florida, Illinois, and Texas, $22 \%$ of the clinics reported not using PAPs at all, primarily because the enrollment process was too complex and time consuming. ${ }^{14}$ The complexity of enrolling patients for these programs stems partly from the fact that many applicants may have multiple prescribed medications. A study of a PAP outreach and assistance program in Maryland, for example, found that patients applied to an average of 5 different PAPs to meet their medication needs. ${ }^{15}$ Patients may also be unaware of available financial assistance for prescription medications. A patient prescription coordinator, who is trained to optimize PAPs, can stay up to date with changing program requirements and use this specialized knowledge to help eligible patients access all available prescription drug assistance.

In 2008, a pilot program, the Spokane Prescription Assistance Network (SPAN), was initiated in Spokane, Washington, to assist low-income adults with accessing affordable prescription medications. The program was developed by the Prescription Drug Assistance Foundation, a nonprofit organization established by the Washington state legislature in 2005. ${ }^{16} \mathrm{~A}$ SPAN patient prescription coordinator served as the central contact for this program and accepted referrals from area health clinics, social service organizations, pharmacies, hospitals, or other providers with patients who need help accessing PAPs. The coordinator worked from multiple community-based locations, such as a senior activity center or a community center or clinic, and met with clients in the SPAN office or at a location convenient to the patient. During the initial assessment, the patient prescription coordinator, who had a master's degree in social work, reviewed the client's prescribed medications, insurance status, and income eligibility based on filed tax returns. The coordinator then identified the PAPs that provided necessary medications at no or reduced cost and assisted the client with the application. Medications were verified by the prescriber, who also signed the PAP application. The SPAN program maintained patient records on prescription refills and helped process PAP renewal applications as needed. The patient prescription coordinator conducted follow-up appointments by phone or in-person to evaluate the prescription needs and overall health of each client, using a structured health assessment.

Regular communication with patients occurred every 3 to 12 months for the purpose of checking self-reported prescription drug adherence and monitoring patient health status. The patient prescription coordinator also communicated with health care providers to resolve questions about medication use or side effects. The underlying aim of SPAN was to reduce unnecessary and avoidable health care encounters for patients having difficulty accessing prescription medications. To determine if this objective was realized, this study sought to empirically assess changes in the frequency of emergency department visits and hospitalizations in the period before and after SPAN enrollment.

\section{Methods}

All patients referred to SPAN received an initial screening interview to determine if they were eligible for one of the many manufacturer prescription assistance programs available. Income guidelines and qualifications vary by PAP, and if the patient prescription coordinator believed that the patient was eligible for one of these programs, the patient received initial assistance with applying for subsidized prescriptions and ongoing help managing medications and renewals. This longitudinal study included all patients who qualified for 
prescription financial assistance and received assistance from the SPAN patient prescription coordinator between March 1, 2009, and August 31, $2012(n=461)$. A comparison group of eligible nonparticipants was not available for this study, since all eligible individuals received a referral to the program. Evaluation procedures were reviewed and approved by the Institutional Review Board-Spokane.

\section{Data Collection}

At the initial screening interview, SPAN participants were asked to join in the research study through an informed consent process. The SPAN patient prescription coordinator described the purpose of the research and answered questions posed by potential participants. SPAN participants who refused consent were excluded from the research $(n=151)$. The research study sample included 310 adults, aged 18 years and older (Figure 1). Data on the demographic background and currently prescribed medications for research participants were collected. Research participants also consented to having their medical records reviewed for emergency department visits and inpatient hospital admissions that occurred within the county. An electronic download of these records was obtained and provided to the research dataset. Finally, in-person or telephone interviews were conducted by the patient prescription coordinator to monitor changes in medication and participant health status at $6,12,24$, and 36 months following program enrollment. Recorded results from these structured interviews were also added to available study records.

\section{Measurement}

Demographic covariates included sex and age at the initial screening interview. Upon initial entry to the SPAN program, and at follow-up interviews thereafter, participants were asked a series of 8 questions from the Short-Form 8 (SF-8) Health Survey. ${ }^{17}$ The SF- 8 has been shown to provide a reliable measure of health-related quality of life for individuals in medication access programs. ${ }^{18}$ The questionnaire items on the SF-8 represent various dimensions of overall health and can be collapsed into a physical component summary and mental component summary score. Both summary scores are norm-referenced (mean $=50$, standard deviation $[S D]=10$ ), so results can be interpreted relative to the general U.S. population. Finally, a record of prescribed medications and providers was maintained and updated by the SPAN program office. Prescribed medications were categorized by therapeutic class using the American Hospital Formulary Service (AHFS) PharmacologicTherapeutic Classification System. The most common classifications-medications related to treating diabetes, mental health, cardiovascular, and pulmonary conditions-were examined and included as covariates in multivariable models examining changes in health care utilization before and after enrollment in SPAN.

\section{TABLE 1 Characteristics of Study Sample at Baseline}

\begin{tabular}{|c|c|c|}
\hline Study Sample $(n=310)$ & \multicolumn{2}{|c|}{ Percentage (n) } \\
\hline \multicolumn{3}{|l|}{ Sex } \\
\hline Female & 66.5 & $(206)$ \\
\hline Male & 33.5 & $(104)$ \\
\hline \multicolumn{3}{|l|}{ Age (years) } \\
\hline $18-34$ & 21.9 & $(68)$ \\
\hline $35-44$ & 19.0 & $(59)$ \\
\hline $45-54$ & 30.3 & (94) \\
\hline $55-64$ & 26.5 & $(82)$ \\
\hline 65 plus & 2.3 & $(7)$ \\
\hline \multicolumn{3}{|l|}{ Physical component summary } \\
\hline Less than 40 & 56.0 & $(173)$ \\
\hline $41-50$ & 23.6 & $(73)$ \\
\hline Greater than 50 & 20.4 & (63) \\
\hline \multicolumn{3}{|l|}{ Mental component summary } \\
\hline Less than 40 & 51.8 & (160) \\
\hline $41-50$ & 29.8 & $(92)$ \\
\hline Greater than 50 & 18.4 & $(57)$ \\
\hline \multicolumn{3}{|c|}{ Prescribed medications (duplicated) ${ }^{\mathrm{a}}$} \\
\hline Antihyperglycemic ${ }^{b}$ & 21.6 & $(67)$ \\
\hline Psychotropic $^{c}$ & 60.3 & (187) \\
\hline Cardiovasculard & 41.9 & (130) \\
\hline Pulmonarye & 30.0 & (93) \\
\hline At least 1 of the above & 93.9 & $(291)$ \\
\hline \multicolumn{3}{|c|}{ Median (IQR) } \\
\hline Age & 48 & $(36-55)$ \\
\hline Physical component summary & 37.5 & $(28.2-48.3)$ \\
\hline Mental component summary & 38.3 & $(28.9-47.1)$ \\
\hline Total medications prescribed & 3 & $(2-6)$ \\
\hline Total medications: PAP assistance & 2 & $(1-3)$ \\
\hline \multicolumn{3}{|c|}{ 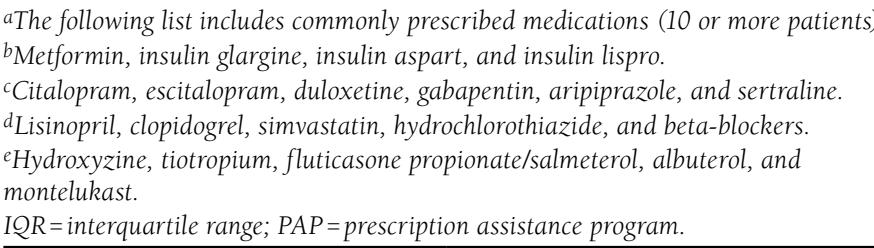 } \\
\hline
\end{tabular}

The primary study outcome was based on the number of acute care encounters, measured as a single variable that combined emergency department visits and inpatient hospital admissions. If a patient visited the emergency department and was later admitted to the hospital, only 1 encounter was recorded as an inpatient hospital admission. Acute care encounters were aggregated for each calendar quarter, and patients with at least 4 calendar quarters of follow-up encounter data were considered in the analysis.

\section{Statistical Analysis}

A mixed-effects generalized regression model was constructed to account for the correlation between measurements on the same subject in different quarters. ${ }^{19,20}$ Based on the zeroinflated count of acute care encounters, a negative binomial 


\section{FIGURE 2 Number of Acute Care Encounters in Period Before and After SPAN Enrollment}

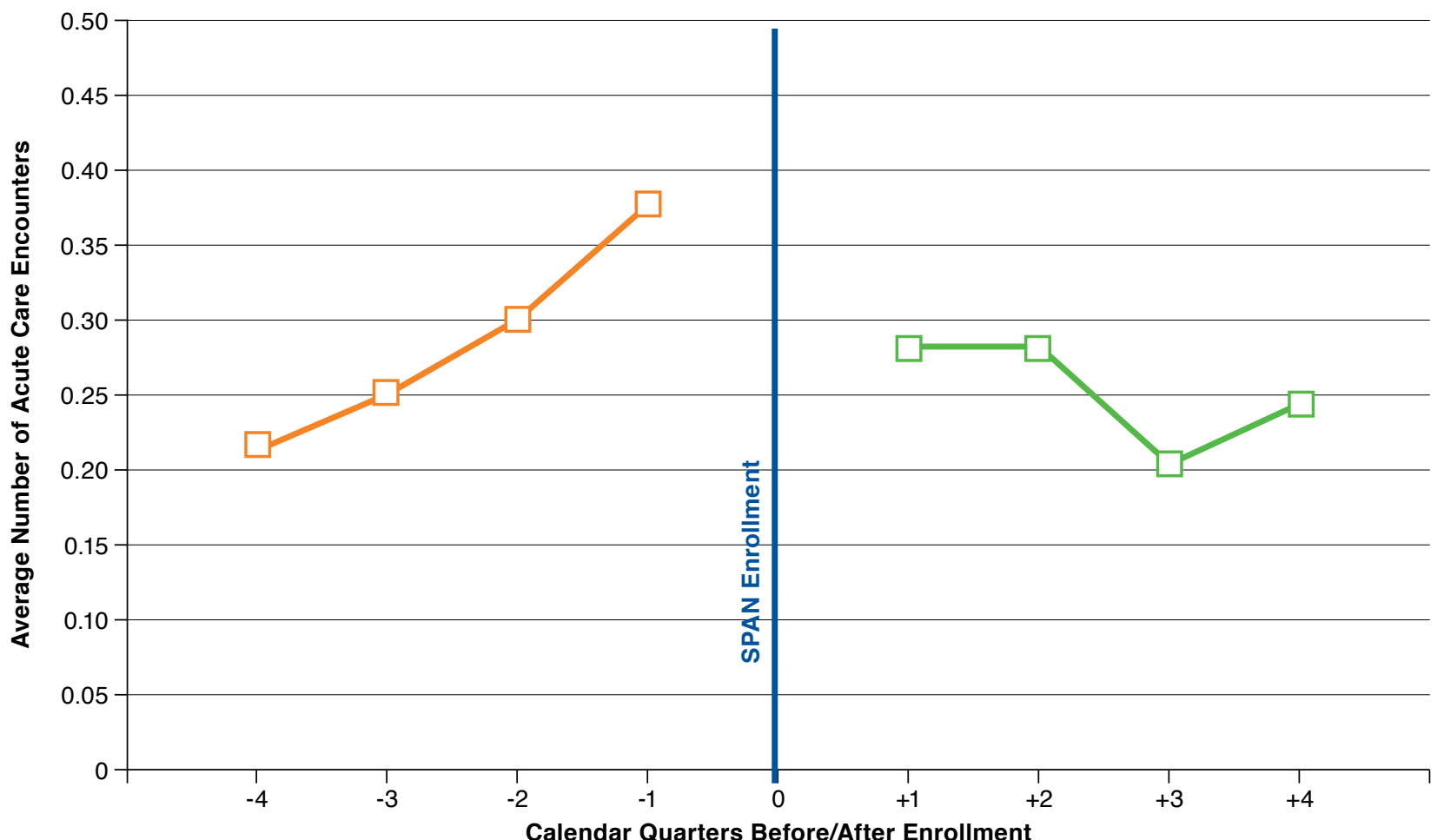

\begin{tabular}{l|r|r|r|r|r|r|r|r}
\hline Mean encounters & 0.216 & 0.252 & 0.300 & 0.377 & 0.281 & 0.281 & 0.203 & 0.242 \\
\hline Maximum encounters & 5 & 4 & 17 & 8 & 11 & 7 & 7 & 9 \\
\hline Participants & 267 & 260 & 254 & 238 & 259 & 260 & 267 & 265 \\
\hline Zero encounters & 29 & 32 & 43 & 45 & 30 & 33 & 33 & 29 \\
\hline l encounter & 14 & 18 & 13 & 27 & 21 & 17 & 10 & 16 \\
\hline 2 or more encounters & 310 & 310 & 310 & 310 & 310 & 310 & 310 \\
\hline Total participants
\end{tabular}

SPAN =Spokane Prescription Assistance Network.

distribution and link function was selected. Both intercept and slope (time in quarters) measurements were included as random effects in the model. The main exposure of interest, SPAN participation, was a dichotomous indication of individuallevel program enrollment (i.e., enrolled yes/no). This repeated measures analysis, controlling for within-subject variation, allowed us to determine whether program participation was related to changes in the rate or incidence of acute care utilization over time.

Statistical analyses were conducted in Stata, version 13 (StataCorp, College Station, TX). Univariate distributions are reported using the median and interquartile range (IQR). Fixed-effects coefficients from the mixed-effects model were exponentially transformed to produce estimates of the incidence rate ratio (IRR). A significance level of 0.05 was chosen a priori for all analyses.

\section{Results}

Nearly two-thirds of SPAN participants were female with a median age of 48 years (Table 1). Study members had healthrelated quality of life scores that were significantly below that of similarly aged U.S. adults. Using the normalized scales from the SF-8 Health Survey, a score of 50 indicates average health. At program entry, SPAN participants had SF-8 scores that were below 40-over 2 standard deviations lower than norms for the general U.S. population in scales related to physical (median=37.5, IQR=28.2-48.3) and mental (median=38.3, $\mathrm{IQR}=28.9-47.1)$ functioning. Study participants were prescribed a median of 3 prescription medications per person $(\mathrm{IQR}=2-6)$ at program entry. According to program records, the SPAN patient prescription coordinator provided participants with access to financial assistance for a median of 2 of the 3 prescriptions (IQR=1-3). The most common 


\begin{tabular}{|c|c|c|}
\hline \multicolumn{3}{|c|}{$\begin{array}{l}\text { Acute Care Encounter Incidence } \\
\text { Rate Ratios, 1-Year Preenrollment } \\
\text { and Postenrollment }\end{array}$} \\
\hline Variable $(n=310)$ & $\begin{array}{c}\text { Adjusted IRR } \\
(95 \% \mathrm{CI})\end{array}$ & $P$ Value \\
\hline Intercept & $0.22 \quad(0.08-0.57)$ & 0.002 \\
\hline Female & $1.20 \quad(0.82-1.77)$ & 0.344 \\
\hline \multicolumn{3}{|l|}{ Age group (years) } \\
\hline $18-34$ & $4.82 \quad(2.78-8.37)$ & $<0.001$ \\
\hline $35-44$ & $2.38 \quad(1.33-4.26)$ & 0.003 \\
\hline $45-54$ & $1.60 \quad(0.98-2.62)$ & 0.062 \\
\hline 55-plus & reference & \\
\hline Physical component summary score & $0.97 \quad(0.95-0.98)$ & $<0.001$ \\
\hline Mental component summary score & $0.99 \quad(0.98-1.00)$ & 0.221 \\
\hline SPAN participation & $(0.31-0.77)$ & 0.002 \\
\hline \multicolumn{3}{|l|}{ Medication class and interactions } \\
\hline Antihyperglycemic by SPAN & $1.51 \quad(0.93-2.46)$ & 0.097 \\
\hline Psychotropic by SPAN & $(1.32-3.24)$ & 0.001 \\
\hline Cardiovascular by SPAN & $1.15 \quad(0.79-1.69)$ & 0.463 \\
\hline Pulmonary by SPAN & $(0.37-0.92)$ & 0.019 \\
\hline Slope random effect (calendar quarter) & $0.00 \quad(0.00-0.00)$ & \\
\hline Intercept random effect & $1.33 \quad(0.95-1.85)$ & \\
\hline \multicolumn{3}{|c|}{$\begin{array}{l}\text { Note: Log likelihood: }-1348.61 ; \text { LR test (vs. negative binomial regression: } \\
\text { chi2(2) = 201.92; } P<0.001) \text {. } \\
C I=\text { confidence interval; } I R R=\text { incident rate ratio; LR=likelihood-ratio; } \\
\text { SPAN = Spokane Prescription Assistance Network. }\end{array}$} \\
\hline
\end{tabular}

prescriptions (92\%) were for psychotropic, cardiovascular, antihyperglycemic/diabetic, or pulmonary medications at program entry. More than $60 \%$ of the study sample $(n=187)$ had at least 1 prescribed psychotropic medication upon SPAN enrollment.

Results from the mixed-effects model of acute care encounters are based on counts of encounters in the 4 quarters (1 year) before and after enrollment in SPAN. In each quarterly observation period before and after enrollment in the program, approximately $85 \%$ of the study sample had zero acute care encounters. The mean number of encounters per participant increased from 0.22 to 0.38 acute care encounters per quarter in the 4 quarters leading up to enrollment. In the first quarter following enrollment, the mean number of acute care encounters dropped to 0.28 acute care encounters per quarter and continued to fall through the fourth quarter (1 year) following enrollment (Figure 2).

The final, fully adjusted model indicated that SPAN participation was independently associated with a lower incidence rate ratio $(\mathrm{IRR}=0.49 ; 95 \%$ confidence interval $[\mathrm{CI}]=0.31-0.77$; $P=0.002$ ) for acute care encounters (Table 2). Age was inversely related to acute care utilization rates. Younger age groups were more likely to use acute care services throughout the observation periods, with a marked increase in the youngest adults at ages $18-34$ years (IRR $=4.82 ; 95 \% \mathrm{CI}=2.77-8.37 ; P<0.001)$. Factor interactions showed that participants with prescribed psychotropic medications experienced a higher acute care uti- lization rate $(\mathrm{IRR}=2.07 ; 95 \% \mathrm{CI}=1.32-3.24 ; P=0.001$ ), while participants with pulmonary medications were associated with a lower acute care rate $(\mathrm{IRR}=0.58 ; 95 \% \mathrm{CI}=0.37-0.92$; $P=0.019)$ relative to participants with other prescribed medication classes.

\section{Discussion}

The results from this study revealed that facilitated enrollment in PAPs was associated with an overall reduced rate of acute care utilization. Decreased acute care utilization was particularly prominent in users of pulmonary medication. Participants receiving psychotropic medications, however, had an increased likelihood of an emergency department or hospital encounter. In addition, the adjusted risk for acute care encounters was highest for younger adults, relative to patients aged 35 years and older. These data suggest that PAPs as currently constructed may improve utilization outcomes in many, but not all, groups of program participants.

Systematic reviews of available literature have found only a limited number of published studies that evaluate the effectiveness of pharmaceutical patient assistance programs or examine outcomes for patients receiving enrollment assistance with PAPs. ${ }^{21}$ Assessments of the impact of these programs are hindered by a lack of longitudinal data for a sizeable study sample. ${ }^{22,23}$ The SPAN program in the state of Washington represents a unique effort by policymakers and practitioners to simplify access to PAPs and track acute care utilization and quality of life outcomes for individuals receiving financial assistance with prescription medications.

While the study period for this analysis took place before the implementation of the PPACA, the implementation of health care reform has not eased concerns about the costs of prescription medications. In a 2015 poll conducted by the Kaiser Family Foundation, the top 2 health care concerns expressed by respondents related to the price of prescription drugs. ${ }^{24}$ Among those surveyed, $76 \%$ listed "making sure that high-cost drugs for chronic conditions are affordable to those who need them" as a priority, and 60\% expressed a need for "government action to lower prescription drug prices." 25 Given the ongoing unease with high prescription drug costs, the need for PAPs will likely continue. Health insurance exchanges, or marketplaces, enacted under the PPACA are increasing coverage options for individuals. However, even under these plans, patients may face high costs for prescription medications or have difficulty obtaining approval for needed medications. ${ }^{26}$

Patients cite difficulty paying for prescriptions as one of the most common reasons for failing to refill or regularly take medications. ${ }^{27,28}$ Substantial evidence has shown that as a patient's share of costs increases, medication adherence declines and health outcomes worsen ${ }^{29,30}$ As health reform in the United States unfolds, the affordability of prescription medications should be monitored, particularly among 
low-income individuals with chronic health conditions. This study shows that increased medication access for participants in this pilot program was associated with an overall reduction in the number of acute care encounters. Reduced acute care utilization was particularly prominent in users of pulmonary prescription medications, suggesting that participants requiring pulmonary medications may especially benefit from prescription assistance. To the contrary, this study reported an increased likelihood of acute care utilization among younger adults and users of psychotropic medications. It is possible that increasing access to drug treatment also raises awareness and concerns about health that, in turn, lead to utilization for younger adults and patients with mental health conditions. More comprehensive coordination of care by PAPs and health care systems may be necessary to effectively address chronic conditions and optimize use of available resources for high-risk groups.

\section{Limitations}

The findings of this study are limited by the lack of a suitable comparison group that could provide detail on outcomes for patients who did not receive SPAN assistance. A randomly assigned control group was not feasible for this project given the desire of program administrators to serve all referred cases. Information on patients who did not consent to the research study was also unavailable, so we were unable to determine if study participants were representative of all referred patients. The generalizability of findings is also constrained by the fact that the relatively small study sample was derived from a single community health system. Additionally, outcomes data may be missing for some study participants. While electronic records provided detailed information about encounters within this region, it is possible that emergency department or inpatient hospital visits that occurred outside the region were excluded.

\section{Implications for Research and Practice}

This study adds to a broader collection of research on navigator programs that are designed to connect vulnerable patient populations to appropriate health care and support services. Studies that measure the impact of navigator programs indicate that patient navigation services in the hospital setting are associated with decreased odds of returning to the emergency department and reduced length of stay for hospital admissions. ${ }^{31,32}$ While the findings presented here are subject to the stated limitations, this study on patient prescription coordination has notable strengths, as well. The 1-year time periods before and after SPAN participation provide an extended analysis of acute care utilization. Based on the declining utilization patterns observed, there may be potential cost savings from the coordinated connecting of patients to PAPs, given the high costs associated with acute care services. Future studies should be designed to also evaluate the costeffectiveness of coordinated medication assistance.

\section{Conclusions}

Pharmaceutical companies have created nearly 200 different subsidized programs to provide free or low-cost medications to income-eligible patients. However, enrolling in these programs can be confusing and time consuming. A centrally coordinated program, such as SPAN, facilitates access to PAPs for people in need of prescription medication. Results from this pilot program indicate that increased access to prescription assistance may prove valuable for reducing emergency department visits and inpatient hospital admissions.

\section{Authors}

MASON H. BURLEY, MPA, is a PhD Candidate, Health Policy and Administration and College of Nursing, and JOHN R. WHITE, JR., PA-C, PharmD, is Chair and Professor, Department of Pharmacotherapy, Washington State University, Spokane. KENN B. DARATHA, PhD, is Associate Professor, College of Nursing, Washington State University, Spokane, and Research Consultant, Providence Medical Research Center, Providence Health Care, Spokane, Washington. KATHERINE TUTTLE, MD, is Executive Director for Research, Providence Medical Research Center, Providence Health Care, Spokane, Washington, and Clinical Professor of Medicine, University of Washington School of Medicine, Seattle. MICHAEL WILSON, MPA, is Health Care Consultant, Providence Medical Research Center, Providence Health Care, Spokane, Washington, and KELLY ARMSTRONG, MSW, is Program Coordinator, Spokane Prescription Assistance Network, Spokane, Washington. STERLING MCPHERSON, PhD, is Assistant Professor and Director, Program of Excellence in Addictions Research, Washington State University, Spokane, and Lead Biostatistician, Providence Medical Research Center, Providence Health Care, Spokane, Washington. SAMUEL SELINGER, MD, is Clinical Investigator, Providence Medical Research Center, Providence Health Care, and Program Founder, Spokane Prescription Assistance Network, Spokane, Washington.

AUTHOR CORRESPONDENCE: Mason H. Burley, MPA, Washington State University, P.O. Box 1495, Spokane, WA 99210-1495. Tel.: 509.358.7620; E-mail: mburley@wsu.edu.

\section{DISCLOSURES}

This study was not supported by any outside funding. The authors declare no conflicts of interest.

Study design was created by Burley, McPherson, and Daratha. Burley Daratha, Selinger, and Armstrong collected the data, with interpretation performed by Burley, Daratha, and Tuttle, assisted by McPherson. The manuscript was written by Burley, Daratha, and Selinger, with assistance from White, and revised by Burley, White, and Selinger, with assistance from Daratha and Tuttle. 


\section{ACKNOWLEDGMENTS}

The authors would like to acknowledge program support provided by Providence Health Care Spokane, Yakima Valley Farm Workers Clinic, HSSA (Health Sciences and Service Authority of Spokane County), and Empire Health Foundation.

\section{REFERENCES}

1. Board of Governors of the Federal Reserve System. Report on the economic well-being of U.S. households in 2014. May 2015. Available at: http://www.federalreserve.gov/econresdata/2014-report-economic-wellbeing-us-households-201505.pdf. Accessed January 23, 2016.

2. Gellad WF, Donohue JM, Zhao X, et al. The financial burden from prescription drugs has declined recently for the nonelderly, although it is still high for many. Health Aff (Millwood). 2012;31(2):408-16

3. Center for Medicare and Medicaid Services. National health expenditure projections 2014-2024, Table 11. Available at: http://www.cms.gov/ Research-Statistics-Data-and-Systems/Statistics-Trends-and-Reports/ NationalHealthExpendData/NationalHealthAccountsProjected.html Accessed January 23, 2016.

4. Keehan SP, Cuckler GA, Sisko AM, et al. National health expenditure projections, 2014-24: spending growth faster than recent trends. Health Aff (Millwood). 2015;34(8):1407-17.

5. Schumock GT, Li EC, Suda KJ, et al. National trends in prescription drug expenditures and projections for 2015. Am J Health Syst Pharm. 2015;72(9):717-36.

6. Partnership for Prescription Assistance. Facts about PPA. 2015. Available at: https://www.pparx.org/sites/default/files/resources/2015_ppa_fact_ sheet_final.pdf. Accessed January 23, 2016

7. Shelley S. Pharma struggles to manage the complexity of its patient assistance programs. Pharmaceutical Commerce. 2013;8(2):1. Available at: http:// pharmaceuticalcommerce.com/brand_communications?articleid $=26770$. Accessed January 23, 2016.

8. Viswanathan, M, Golin, CE, Jones, CD, et al. Interventions to improve adherence to self-administered medications for chronic diseases in the United States: a systematic review. Ann Intern Med. 2012;157(11):785-95.

9. Partnership for Prescription Assistance. Directory of PhRMA Member Company Patient Assistance Programs. 2015. Available at: https://www. pparx.org/sites/default/files/ppa_directory_june_2015.pdf. Accessed January 23, 2016

10. Castellon YM, Bazargan-Hejazi S, Masatsugu M, Contreras R. The impact of patient assistance programs and the 340B Drug Pricing Program on medication cost. Am J Manag Care. 2014;20(2):146-50.

11. Viale PH, Mister S. Utilization of medication-assistance programs for medically uninsured patients: one public teaching hospital's experience. Clin J Oncol Nurs. 2001:5(6):247-252.

12. Weiner S, Dischler J, Horvitz C. Beyond pharmaceutical manufacturer assistance: broadening the scope of an indigent drug program. Am J Health Syst Pharm. 2001;58(2):146-50.

13. Mounts VL, Ringenberg DG, Rhees K, Partridge C. Implementation of a patient medication assistance program in a community pharmacy setting. J Am Pharm Assoc (2003). 2005;45(1):76-81

14. Duke KS, Raube K, Lipton HL. Patient-assistance programs: assessment of and use by safety-net clinics. Am J Health Syst Pharm. 2005;62(7):726-31.

15. Chauncey D, Mullins CD, Tran BV, McNally D, McEwan RN. Medication access through patient assistance programs. Am J Health Syst Pharm. 2006;63(1):1254-59.
16. Washington State Legislature. Prescription drug assistance foundation-Nonprofit and tax-exempt corporation-Definitions-Liability. RCW 41.05.550. 2005. Available at: http://app.leg.wa.gov/RCW/default. aspx?Cite $=41.05 .550$. Accessed January 23, 2016.

17. Ware JE, Kosinski M, Dewey JE, Gandek B. How to Score and Interpret Single-Item Health Status Measures: A Manual for Users of the SF-8 Health Survey (with a Supplement on the SF-6 Health Survey). Lincoln, RI: QualityMetric; Boston: Health Assessment Lab; 2001.

18. Lefante J, Harmon G, Ashby K, Barnard D, Webber L. Use of the SF-8 to assess health-related quality of life for a chronically ill, low-income population participating in the Central Louisiana Medication Access Program (CMAP). Qual Life Res. 2005;14(3):665-73.

19. Hilbe JN. Negative Binomial Regression. 2nd ed. New York: Cambridge University Press; 2011.

20. Raudenbush SW, Bryk AS. Hierarchical Linear Models: Applications and Data Analysis Methods. Thousand Oaks, CA: Sage Publications; 2002.

21. Felder TM, Palmer NR, Lal LS, Mullen PD. What is the evidence for pharmaceutical patient assistance programs? A systematic review. J Health Care Poor Underserved. 2011;22(1):24-49.

22. Chu CF, Lai L, Felder T, Rosenau P. Evaluation of patient assistance program availability and eligibility for top 200 brand and generic drugs in the United States. Value Health. 2010;13(3):A84. [Abstract PHP 15].

23. Carroll NV. Pharmaceutical patient assistance programs: don't look a gift horse in the mouth or there's no such thing as a free lunch. J Manag Care Pharm. 2007;13(7):614-16. Available at: http://www.amcp.org/data/jmcp/ JMCPMaga_Sept\%2007_614-616.pdf.

24. Caffrey M. Kaiser poll finds strong support to control drug prices. Am J Manag Care. April 21, 2015. Available at: http://www.ajmc.com/focusof-the-week/0415/kaiser-poll-finds-strong-support-to-control-drug-prices. Accessed January 23, 2016.

25. Dijulio B, Firth J, Brodie M. Kaiser health tracking poll: April 2015. The Henry J. Kaiser Family Foundation. Available at: http://kff.org/health-costs/pollfinding/kaiser-health-tracking-poll-april-2015/. Accessed January 23, 2016.

26. Pharmaceutical Research and Manufacturers of America. PhRMA fact sheet. Out-of-pocket costs on health insurance exchanges. 2014. Available at: http://www.phrma.org/fact-sheet/outofpocket-costs-on-health-insuranceexchanges. Accessed January 23, 2016.

27. McGuire M, Iuga M. Adherence and health care costs. Risk Manag Healthc Policy. 2014;7:35-44. Available at: http://www.ncbi.nlm.nih.gov/pmc/articles/ PMC3934668/. Accessed January 23, 2016.

28. Kennedy J, Tuleu I, Mackay K. Unfilled prescriptions of Medicare beneficiaries: prevalence, reasons, and types of medicines prescribed. J Manag Care Pharm. 2008; 14(6):553-60. Available at: http://www.amcp.org/data/jmcp/ JMCPMaga_553-560.pdf. Accessed January 23, 2016.

29. Viswanathan M, Golin CE, Jones CD, et al. Interventions to improve adherence to self-administered medications for chronic diseases in the United States: a systematic review. Ann Intern Med. 2012;157(11):785-95.

30. Eaddy MT, Cook CL, O'Day K, Burch SP, Cantrell CR. How patient costsharing trends affect adherence and outcomes: a literature review. P T. 2012;37(1):45-55

31. Enard KR, Ganelin DM. Reducing preventable emergency department utilization and costs by using community health workers as patient navigators. J Healthc Manag. 2013;58(6):412-27.

32. Kwan JL, Morgan MW, Stewart TE, Bell CM. Impact of an innovative inpatient patient navigator program on length of stay and 30-day readmission. J Hosp Med. 2015;10(12):799-803. 